\title{
EOLÉTIOA volum 33,2013 química \\ DETERMINAÇÃO DO NÚMERO DE CICLOS DE REUSO DO ADSORVENTE CINZA DE CASCA DE ARROZ NO TRATAMENTO DE UM BANHO RESIDUAL DE TINGIMENTO TÊXTIL
} Artigo/Article

\author{
Ivonete O. Barcellos1*; Thyego de Lima1; Ana Maria Blosfeld2
}

1-Departamento de Química - Campus I, FURB, Rua Antônio da Veiga, 140, 89012-900, Blumenau - SC

2-Instituto FURB de Serviços, Pesquisa e Inovação, FURB, Rua São Paulo, 3366, Campus II Bloco P. 89030-000 Blumenau - SC.

Este estudo avaliou um sistema de fluxo contínuo utilizando cinzas de casca de arroz como adsorvente para tratamento do banho residual de tingimento têxtil. O sistema consistiu na recirculação do efluente numa bureta contendo o adsorvente. Este procedimento foi realizado em cinco ciclos de reutilização do adsorvente. A Demanda Química de Oxigênio e Cor foi determinada pela estimativa da eficiência do adsorvente em função do tempo, comparando os ciclos de reuso das águas residuais, antes e depois de tratadas com cinzas. A máxima eficiência obtida foi de $91 \%$ no $1^{\circ}$ ciclo. No entanto, no ciclo 5 , a eficiência do adsorvente foi em torno de $46 \%$.

Palavras chave: adsorção, cinza de casca de arroz, corantes reativos.

\begin{abstract}
This study evaluated a continuous flow system using rice husk ash as an adsorbent to treat textile bath dyeing residual. The system consisted in recirculating the effluent in a burette containing the adsorbent. This procedure was performed in five cycles of reuse of the adsorbent. Chemical Oxygen Demand and color were determined by the estimate of the adsorbent's efficiency as a function of time by comparing the cycles of reuse bath dying residual, raw wastewater and wastewater treated with ashes. The maximum efficiency obtained was $91 \%$ in the $1^{\text {st }}$ cycle. However, in the $5^{\text {th }}$ cycle the efficiency adsorbent was near $46 \%$.
\end{abstract}

Key words: adsorption, rice husk ash, reactive dyes

\section{INTRODUÇÃO}

O crescimento populacional e principalmente industrial, nas últimas décadas, vem sendo marcadas por episódios lamentáveis de poluição e destruição do meio ambiente. Isto pode ser observado através de alterações na qualidade do solo, água e ar [1].
As indústrias de beneficiamento têxtil apresentam níveis elevados de consumo de água por quilo de malha beneficiada, em torno de 50 a $100 \mathrm{~L}$ por Kg de produto têxtil acabado, sendo este setor responsável por $15 \%$ da água consumida pelas indústrias. Em geral. ao final dos processos de beneficiamento tais como: a preparação, tingimento e acabamento, a água utilizada, ou 
seja, o efluente gerado está contaminado com corantes e diversos produtos auxiliares, entre detergentes, gomas, antiespumantes, formóis, cloro, apresentando assim alta concentração de carga orgânica, além de outras substâncias nocivas ao meio ambiente $[2,3]$.

O método de adsorção utilizando-se de materiais alternativos e naturais como adsorventes vem sendo estudado, visando eficiência e economia em tratamento de efluentes e um melhor aproveitamento de resíduos antes considerados inúteis. ${ }^{4-9}$ Dentre estes destacamos a cinza de casca de arroz, que é um resíduo do agronegócio gerado em abundância e que tem despertado o interesse de pesquisadores por suas propriedades adsorvente [10].

A realização deste trabalho teve como objetivo principal avaliar o número de ciclos de reutilização das cinzas de casca de arroz como adsorvente no tratamento de um banho residual de tingimento têxtil.

\section{A cinza da casca de arroz e suas aplicações}

A produção de arroz na safra 2009/2010 no

Brasil e em Santa Catarina foi estimada em 12016,3 e 1063,8 mil toneladas, respectivamente. Se $23 \%$ deste valor correspondem à casca e $18 \%$ da massa da casca é cinza, a produção de cinzas de casca de arroz corresponde 497474,82 toneladas no Brasil e 44041,32 toneladas em SC $[11,12]$. As empresas beneficiadoras de arroz, que utilizam a casca como combustível para a secagem, parboilização do cereal e aquecimento dos silos de armazenamento, quando não possuem processos para o aproveitamento e/ou descarte adequado das cinzas geradas com a queima essas têm como destino terrenos baldios ou são lançadas em rios e córregos, provocando poluição e contaminação de mananciais e agressão à saúde da população [13].

Várias alternativas tecnológicas têm sido estudadas visando o aproveitamento das cinzas de casca de arroz, geradas na combustão da casca em usinas beneficiadoras de arroz que utilizam este material como combustível [14]. Assim na literatura encontram-se diversos estudos realizados utilizando a cinza de casca de arroz como adsorvente para corantes [4,5,15-18].

Barcellos et al estudaram a cinética de adsorção dos corantes reativos Procion(amarelo H-EXL e marinho H-EXL) em cinzas de casca de arroz. Os estudos foram realizados com soluções monocrômicas desses corantes de 0,01 a 0,08 g.L ${ }^{-}$ ${ }^{1}$, variando-se a concentração do adsorvente entre 30 e 80 g.L $\mathrm{L}^{-1}$. As soluções de corantes foram mantidas sob agitação constante nas temperaturas de $40^{\circ} \mathrm{C}$ e $50^{\circ} \mathrm{C}$. A maior eficiência $(96,2 \%)$ do adsorvente foi com o corante marinho H-EXL, a $50^{\circ} \mathrm{C}$ durante um período de $96 \mathrm{~h}$. Sendo favorecida pelo aumento da temperatura. Baseado nos resultados obtidos nestes experimentos realizados com estas soluções puras de corantes têxteis pode-se concluir que a cinza de casca de arroz poderia ser uma alternativa no tratamento de efluentes têxteis, porém se faz necessário a comprovação experimental com efluentes reais para tal afirmação, uma vez que a presença dos produtos químicos auxiliares dos processos pode afetar o processo de adsorção [4].

Oliveira et al utilizaram cinzas de casca de arroz como adsorvente para a clarificação de óleo residual. Ao óleo foram adicionados $10 \%$ do adsorvente em dois tipos de amostras, a que foi agitada e outra que ficou em repouso por $24 \mathrm{~h}$. Constatou-se um grau de clarificação de $70,62 \%$ para o teste em agitação e 17,93\% para o teste em repouso. Portanto a agitação mostrou-se um parâmetro muito importante no processo de adsorção [18].

Chaves, T. F. et al estudaram a utilização da cinza de casca de arroz na remoção do corante azul de metileno em soluções aquosas, em um período de $24 \mathrm{~h}$ onde a eficiência de remoção do corante atingiu $84 \%$. À medida que o tempo de contato aumentou houve uma elevação na eficiência de remoção, atingindo a faixa de $94 \%$ para o tempo de 48 h [19]. Sharma et al também estudaram a remoção do corante azul de metileno em soluções aquosas utilizando neste caso a casca e a cinza de casca de arroz. Verificaram que o $\mathrm{pH}$ ótimo para o processo foi o neutro e que a eficiência da adsorção aumentava com o 
acréscimo da temperatura. Comparando estudos que utilizaram resíduos agrícolas e industriais como adsorventes (bioadsorventes), constatou-se que entre esses os que possuem máxima capacidade de adsorção são as cinzas de casca de arroz e a casca de arroz [20].

Lakshmi et al estudaram a adsorção do corante Índigo Carmine na cinza de casca de arroz em sistema de batelada. Este corante é muito utilizado em indústrias têxteis e alimentícias e trata-se de um corante aniônico. Neste estudo investigou-se o efeito de fatores como o $\mathrm{pH}$, quantidade do adsorvente, concentração inicial do corante e tempo de contato em relação à eficiência da adsorção. As capacidades de adsorção do corante pelo adsorvente foram de 29.3, 33.5, 40.3 e $65.9 \mathrm{mg} . \mathrm{g}^{-1}$ nas temperaturas de 293, 303, $313 \mathrm{e}$ $323 \mathrm{~K}$ respectivamente. A conclusão dos autores é que a cinza de casca de arroz é um eficiente adsorvente para o corante Índigo Carmine [16].

Ferro e Wiebeck utilizaram a cinza de casca de arroz como carga em matrizes de poliamida 6 e poliamida 6,6. Comparou-se as propriedades mecânicas de resistência a tração, a flexão, ao impacto e a propriedade térmica de fio incandescente entre compostos de poliamida $6 \mathrm{e}$ poliamida 6.6 , com $30 \%$ de cinza de casca de arroz e $30 \%$ de talco como comparativo. Os resultados de propriedades mecânicas e térmica mostraram-se semelhantes entre os testes com o talco e as cinzas de casca de arroz [21].

\section{Efluente têxtil}

O efluente têxtil é geralmente caracterizado pela sua composição extremamente heterogênea, possuindo elevada demanda química de oxigênio (DQO), demanda bioquímica de oxigênio (DBO), cor muito intensa, $\mathrm{pH}$ altamente flutuante, considerável quantidade de metais pesados $(\mathrm{Cr}, \mathrm{Ni}$ ou $\mathrm{Cu})$, surfactantes entre outros $[22,23]$.

A cor não possui parâmetro legal para lançamento de efluentes em corpos receptores, principalmente devido à crença de que compostos que contêm grupos cromóforos não apresentem um apreciável impacto ambiental. No entanto, a cor pode ser altamente interferente nos processos fotossintéticos naturais nos leitos dos rios e em lagoas, provocando alterações na biota aquática principalmente nas imediações da descarga [24,25].

Existem várias classes de corantes utilizados em processos de tingimento na indústria têxtil, como reativos, ácidos, básicos, dispersos, a cuba, sulfurosos, diretos entre outros. A classificação dos corantes está relacionada à sua estrutura química e a natureza da fibra que o corante irá interagir [26,27].

Além dos corantes, também é necessário a adição de uma grande variedade de produtos químicos chamados de auxiliares nos processos de beneficiamento têxtil, para controlar diversas variáveis que influenciam no tingimento, visando assim processos mais eficazes e controlados. Os principais auxiliares utilizados são: sais (cloreto e sulfato de sódio), agentes oxidantes( peróxido de hidrogênio), agentes redutores como o hidrossulfito de sódio, detergentes, sequestrantes, retardantes, igualizantes, umectantes, antiespumantes, amaciantes, ácidos, bases entre outros [22].

Diversas são as técnicas estudadas e empregadas em tratamento de efluentes. Dentre elas destacam-se processos físico-químicos de precipitação-coagulação, tratamento com ozônio, Processos oxidativos avançados utilização de tecnologias de membrana como osmose reversa, microfiltração, ultrafiltração, e a adsorção [28-31].

Chiarello et al utilizaram soluções de corantes reativos Procion amarelo H-EXL, Procion marinho H-EXL e Procion crimson $\mathrm{H}$ EXL tratadas com cinzas de casca de arroz, em tingimentos de tecidos de algodão pré-alvejados, empregando-se os mesmos corantes utilizados nas soluções tratadas por adsorção. A remoção de cor pelo processo de adsorção com cinzas de casca de arroz variou entre $87 \%$ e $98,5 \%$ e os resultados de reutilização foram bons para diluição com $20 \%$ de água destilada, obtendo-se um $\Delta \mathrm{E}=0,24$, representando então uma economia de $80 \%$ com o reuso da água [32]. Chiarello e Barcellos também avaliaram o reuso de soluções de corantes 
ácidos(Erionyl Vermelho A-3B) tratados com farelo da fibra do pseudocaule da bananeira. O índice de remoção do corante em solução foi superior a 90\%. Estas soluções de corantes tratadas foram reutilizadas no tingimento de malhas $100 \%$ poliamida 66 com dois corantes ácidos: Erionyl Vermelho A-3B e Amarelo RXL. Os resultados foram favoráveis apenas para os tingimentos utilizando o corante Erionyl Vermelho A-3B, apresentando um $\Delta \mathrm{E}$ próximo dos limites aceitáveis pela indústria têxtil $(\Delta \mathrm{E} \leq$ 1,0 ), sendo de 1,03 para a solução diluída a $50 \%$ com água destilada e 1,04 para a solução sem diluição. Portanto neste caso a diluição não se faz necessária para melhorar a reprodutibilidade da cor [33].

Batisti et al reaproveitaram efluentes sintéticos tratados por processo de adsorção em tingimentos de tecido $100 \%$ malha náilon $6.6 \mathrm{em}$ escala laboratorial. Produziram-se efluentes sintéticos a partir de tingimentos em tecidos de poliamida com os corantes: vermelho ácido Erionyl A-3B, amarelo ácido Erionyl RXL e marinho ácido Erionyl $\mathrm{R}$ na presença e ausência de auxiliares têxteis. Os rejeitos dos tingimentos foram tratados por processo de adsorção com uma blenda náilon 6.6/quitosana na proporção de 80/20 na forma de flocos, obtendo-se índices de remoção de cor superiores a 95\%. Depois de tratados os rejeitos foram reaproveitados em novos tingimentos de tecidos de poliamida com corantes ácidos em escala laboratorial. Os resultados quanto às propriedades tintoriais (K/S e $\Delta \mathrm{E})$, foram considerados satisfatórios para os banhos dos rejeitos monocrômicos, comparados ao padrão utilizado e os aceitos pelas indústrias $(\Delta \mathrm{E} \leq 1,0)$ [22].

\section{PROCEDIMENTOS EXPERIMENTAIS}

\section{Preparação do adsorvente}

As cinzas de casca de arroz utilizadas foram cedidas por uma empresa de beneficiamento de arroz do Vale do Itajaí (SC). A cinza apresentava cor preta, indicando residual de carbono na mesma. As etapas de preparação das cinzas consistiram de duas lavagens com água a temperatura de $70^{\circ} \mathrm{C}$ a $90 \mathrm{rpm}$ por um período de $24 \mathrm{~h}$ em cada lavagem, sendo posteriormente secas em estufa a $90^{\circ} \mathrm{C}$, e peneiradas em uma malha de 170 mesh, que corresponde a uma granulometria de $88 \mu \mathrm{m}$. Apesar dos experimentos realizados por Barcellos et $A L$ [4] terem apresentado bons resultados utilizando cinzas de casca de arroz com granulometria entre 119 e $296 \mu \mathrm{m}$, optou-se por utilizar neste projeto as cinzas com granulometria menor por ampliar a variedade de granulometria e desta maneira comparar as eficiências obtidos neste trabalho com os da autora.

\section{Coleta da amostra para tratamento}

A amostra para tratamento foi coletada diretamente de uma máquina industrial de tingimento no estágio de neutralização da malha (viscose) após o tingimento. Os corantes presentes no banho residual de tingimento têxtil formavam uma bicromia, sendo o Amarelo remazol ultra RBG e Vermelho remazol RGB gran, ambos reativos e com concentrações de $0,10 \%$ e $1,49 \%$ respectivamente. Produtos auxiliares como antiespumante, dispersante, álcali, anti redutor, cloreto de sódio e neutralizador ácido também fazem parte da receita de tingimento do banho coletado, não informado a especificação pela fonte doadora. A amostra coletada foi armazenada sob refrigeração a $5^{\circ} \mathrm{C}$ durante os experimentos, visando a preservação de suas propriedades físicoquímicas durante os estudos experimentais.

\section{Adaptação do sistema para fluxo contínuo}

O sistema de fluxo contínuo adaptado para tratamento do banho residual de tingimento têxtil utilizando cinza de casca de arroz como adsorvente consiste de uma bomba peristáltica, mangueiras e uma bureta de $100 \mathrm{~mL}$ conforme a figura 1. Dentro da bureta colocou-se um chumaço de algodão para impedir que partículas do adsorvente passassem para as mangueiras da bomba ocasionando entupimentos. Logo acima do chumaço de algodão foi colocado o adsorvente, sobre qual foi adicionado o banho de tingimento 
residual (figura 1a) proveniente da máquina de tingir da empresa.

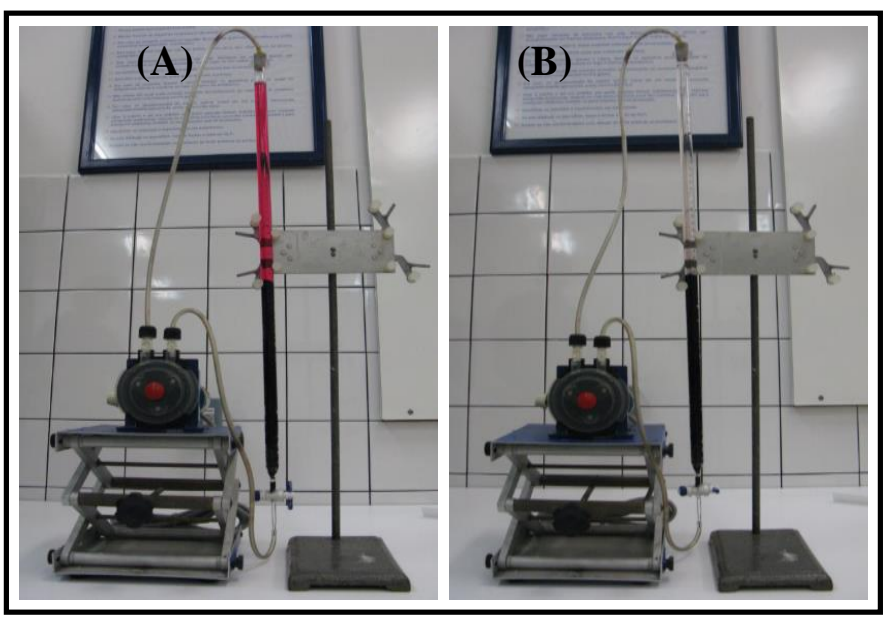

Figura 1 - Foto do sistema de fluxo contínuo para o tratamento com cinzas de casca de arroz. (A) banho de tingimento bruto + cinzas; (B) banho de tingimento tratado + cinzas

\section{Determinação da quantidade ideal de adsorvente}

Para a determinação da quantidade ideal de adsorvente a ser empregada, os testes foram todos realizados com um volume padrão de amostra (banho de tingimento residual) de $100 \mathrm{~mL}$, com vazão fixa de $40 \mathrm{~mL} \cdot \mathrm{min}^{-1} \mathrm{e}$ a temperatura ambiente constante $\left(20 \pm 3^{\circ} \mathrm{C}\right)$. Baseando-se em resultados obtidos em estudos anteriores por Barcellos et al [4], que utilizaram $8 \%(\mathrm{~m} / \mathrm{v})$ de cinzas de casca de arroz em seus estudos de adsorção, realizou-se três testes, com 7\%, $10 \%$ e $13 \%(\mathrm{~m} / \mathrm{v})$ de adsorvente visando avaliar o desempenho do adsorvente quanto a sua eficiência máxima e tempo necessário para atingir a mesma.

\section{Determinação da eficiência do adsorvente em diferentes ciclos de tratamento}

Através de um espectrofotômetro UV visível (Shimadzu - 1601 PC) determinou-se o comprimento de onda de máxima absorção $\left(\lambda_{\text {máx }}\right)$ do banho de tingimento para viabilizar o monitoramento da variação da absorbância da amostra em função do tempo. $\mathrm{O}$ valor do $\lambda_{\text {máx }}$ encontrado foi de $506 \mathrm{~nm}$.
Para a determinação do número de ciclos de reuso em função da eficiência do adsorvente monitorou-se a absorbância da amostra em função do tempo de processo, sendo a medida da absorbância o indicador de eficiência do adsorvente. A medida que a eficiência demonstrava taxas muito pequenas de aumento em função do tempo ou até estabilizar (equilíbrio), o experimento era interrompido, caracterizando um ciclo de adsorção. Para começar um novo ciclo de adsorção apenas se retirava a amostra já tratada da bureta, adicionando-se uma nova amostra não tratada de mesma procedência. Assim repetiu-se o procedimento para a determinação do número de ciclos de reuso do adsorvente, fixando-se o parâmetro de eficiência de no mínimo $50 \%$. Os percentuais de eficiência (E) foram determinados de acordo com a Equação1:

$$
E(\%)=\frac{A b s_{i}-A b s_{f}}{A b s_{i}} x 100
$$

\section{Análises físico-químicas dos banhos de tingimento}

Foram realizadas análises físico-químicas de cor e DQO (Demanda Química de Oxigênio) com as amostras dos banhos antes e pós tratamento com cinzas de casca de arroz. Para garantir a veracidade dos resultados os testes foram realizados em triplicata, porém são apresentados apenas as médias dos resultados.

\section{Cor aparente (PtCo)}

Utilizou-se um espectrofotômetro $\mathrm{HACH}$ 2800 para a determinação de cor das amostras. O instrumento possui uma curva de calibração de cor (PtCo) em função da absorbância da amostra em $455 \mathrm{~nm}$. O método utilizado foi o HACH 8025 (APHA Platinum-Cobalt Standard Method).

\section{Demanda química de oxigênio (DQO)}

Utilizou-se um reator de DQO HACH, espectrofotômetro HACH 2800 e kit de reagentes HACH para determinação de DQO. O método utilizado foi o HACH 8000 (Reactor Method Digestion). $\mathrm{O}$ princípio do método baseia-se na digestão da amostra a $150^{\circ} \mathrm{C}$ por um período de $2 \mathrm{~h}$ 
em um meio aquoso oxidante. Após a digestão é conferida uma certa coloração a amostra, e através da absorbância em $620 \mathrm{~nm}$ determina-se a DQO da amostra, justo que o instrumento possui uma curva de calibração da DQO em função da absorbância.

\section{RESULTADOS E DISCUSSÃO}

\section{Otimização das quantidades do adsorvente}

Este experimento teve como objetivo verificar qual a quantidade ideal de adsorvente a ser utilizada nos estudos de adsorção. Foi levado em consideração principalmente o tempo necessário para estabilização do processo de adsorção bem como a eficiência do adsorvente (\%) determinada a partir da equação1.

Foram obtidas nos três experimentos eficiências máximas relativamente próximas, sendo de $94 \%$, 91\% e $93 \%$ para o teste com $7 \mathrm{~g}$, $10 \mathrm{~g}$ e $13 \mathrm{~g}$ de adsorvente, respectivamente. Porém o que se diferenciou muito entre os testes foi o tempo necessário para que estabelece-se o equilíbrio de adsorção, sendo de aproximadamente 97h para o teste com $7 \mathrm{~g}, 22 \mathrm{~h}$ para o teste com $10 \mathrm{~g}$ e apenas $3 \mathrm{~h}$ para o teste com 13g, conforme mostra figura 2.

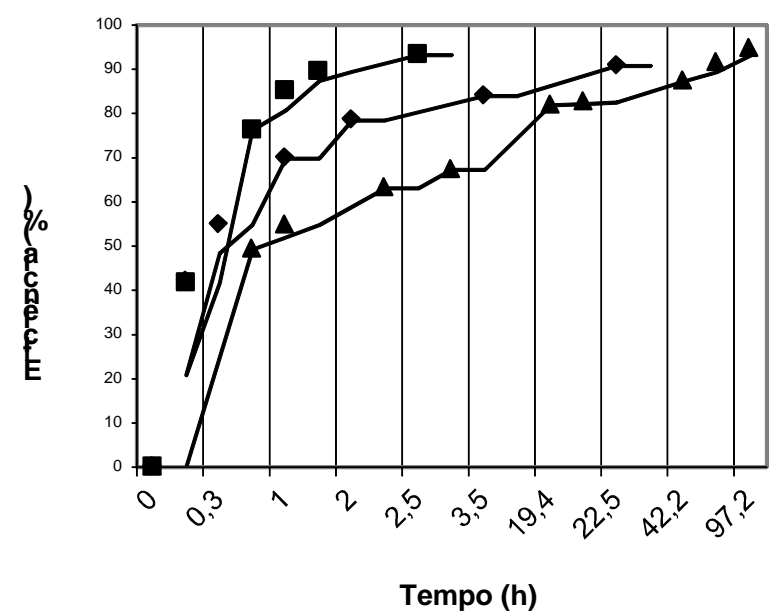

Figura 2 - Gráfico de eficiência do adsorvente em função do tempo utilizando 7, 10 e $13 \mathrm{~g}$ do adsorvente.
$\Delta 7 \mathrm{~g}$
- $10 \mathrm{~g}$
- $13 \mathrm{~g}$

Das três alternativas testadas optou-se por utilizar $10 \mathrm{~g}$ do adsorvente, visto que em comparação ao teste com $7 \mathrm{~g}$ necessitou de apenas de $23 \%$ do tempo para atingir o equilíbrio de adsorção com eficiências muito próximas e elevadas para remoção da cor (Figura 1b). O teste com $13 \mathrm{~g}$ foi o que apresentou um melhor desempenho no que diz a respeito ao tempo necessário para se atingir o equilíbrio de adsorção, correspondendo a $2,6 \%$ e $11 \%$ do tempo necessário para que os testes com $7 \mathrm{~g}$ e $10 \mathrm{~g}$ atingissem o equilíbrio respectivamente. Optou-se por não utilizar $13 \mathrm{~g}$ do adsorvente, pensando-se na possibilidade de utilizar o adsorvente em uma planta real de ETE. Comparando-se as massas de 10 e $13 \mathrm{~g}$ do adsorvente verifica-se um acréscimo de $30 \%$, o que representaria uma elevada quantidade de adsorvente, considerando que a vazão média de uma indústria têxtil de médio/grande porte é cerca de $150 \mathrm{~m}^{3} \cdot \mathrm{h}^{-1}$.

Ahmad e Hameed[5] utilizando carvão ativado de restos de bambu no tratamento de um efluente têxtil real atingiram um índice de eficiência de $91,8 \%$ utilizando apenas $0,3 \mathrm{~g}$ de adsorvente por $100 \mathrm{~mL}$ de efluente em um tempo de $10 \mathrm{~h}$. Comparando o experimento o qual foi utilizado $10 \mathrm{~g}$ de adsorvente com o resultado da literatura [5], verifica-se que as quantidades de adsorvente utilizada e o tempo necessário para o equilíbrio de adsorção foram superiores, porém é valido ressaltar que o carvão ativado de restos de bambu foi preparado através de um método químico, encarecendo o processo e gerando resíduos ambientais, enquanto que em nosso estudo as cinzas são resíduos utilizados neste caso sem tratamento prévio.

\section{Ciclos de reutilização}

A partir dos parâmetros pré-fixados iniciou-se a seqüência de testes visando avaliar eficiência do adsorvente na remoção dos corantes do banho de tingimento em função dos ciclos de reutilização do mesmo.

A figura 3 mostra que a eficiência máxima ( $91 \%$ ) do teste ocorre no tempo de 50,5h, porém no tempo de aproximadamente $22 \mathrm{~h}$ taxa de 
aumento da eficiência já era muito pequena tendo uma diferença de apenas 0,3\% em um tempo de $28 \mathrm{~h}$ para o primeiro ciclo de tratamento. Desta maneira pode-se considerar que com o tempo de $22 \mathrm{~h}$ o adsorvente teria atingindo a sua eficiência máxima viável considerando também o tempo como um indicador de eficiência. É possível verificar também que a taxa de eficiência decresce com o aumento do tempo, tendendo a estabilizar em tempo infinito. Barcellos et al [31] utilizando cinzas de casca de arroz como adsorvente no tratamento de soluções de corantes reativos, obtiveram uma eficiência máxima do adsorvente de $96 \%$ em um tempo de 96h utilizando 80 g. $\mathrm{L}^{-1}$ de adsorvente. Apesar da eficiência deste experimento ter sido inferior comparada à apresentada pelos autores acima citados, verificase que o tempo necessário para o equilíbrio de adsorção neste experimento foi muito menor. $\mathrm{O}$ sistema utilizado para o processo de adsorção foi diferente, sendo que os autores [31] utilizaram sistema de batelada sob agitação constante em temperaturas de $40^{\circ} \mathrm{C}$ e $50^{\circ} \mathrm{C}$, onde observaram que $\mathrm{o}$ acréscimo na temperatura favoreceu $\mathrm{o}$ processo de adsorção. Enquanto que os experimentos deste trabalho foram realizados por sistema de fluxo contínuo a temperatura ambiente $\left(20 \pm 3^{\circ} \mathrm{C}\right)$.

No ciclo $\mathrm{n}^{\circ} 02$ do tratamento a eficiência do adsorvente diminuiu cerca de 1,3\% do tempo de $95 \mathrm{~h}$ para $104 \mathrm{~h}$ e isto pode acontecer em função do equilíbrio de adsorção deste sistema. Com o tempo de $99 \mathrm{~h}$ o adsorvente atingiu sua eficiência máxima do teste, sendo esta de $86 \%$, isto porque o adsorvente começa a apresentar diminuição dos sítios disponíveis para adsorção.

Observa-se que a eficiência máxima obtida no ciclo $\mathrm{n}^{\circ} 03$ de reutilização do adsorvente foi de $74 \%$ no tempo de aproximadamente 160 h. Porém percebe-se que no tempo $144 \mathrm{~h}$ onde a eficiência era de $73 \%$ para 160,3 horas a eficiência aumentou apenas 1,4\%, julgando-se ser um aumento muito pequeno para um tempo de $16,4 \mathrm{~h}$, portanto desnecessário.

No ciclo $\mathrm{n}^{\circ} 04$ do tratamento a eficiência máxima obtida no teste foi de $60 \%$ para um período de $160 \mathrm{~h}$. Entretanto percebe-se que a partir de $40 \mathrm{~h}$ a taxa de aumento da eficiência do adsorvente diminuiu muito.

Enquanto para o ciclo $\mathrm{n}^{\circ} 05$ do tratamento a eficiência máxima foi de aproximadamente 46 $\%$ em $139 \mathrm{~h}$, porém no tempo de $120 \mathrm{~h} \mathrm{a}$ eficiência já havia atingido $45 \%$ perfazendo uma diferença de apenas 0,5\% em um tempo de 19,2 h. Este foi o último teste de reuso das cinzas, visto que se fixou previamente como parâmetro para a avaliação do $\mathrm{n}^{\mathrm{o}}$ de ciclos de uso do adsorvente uma eficiência mínima de $50 \%$.

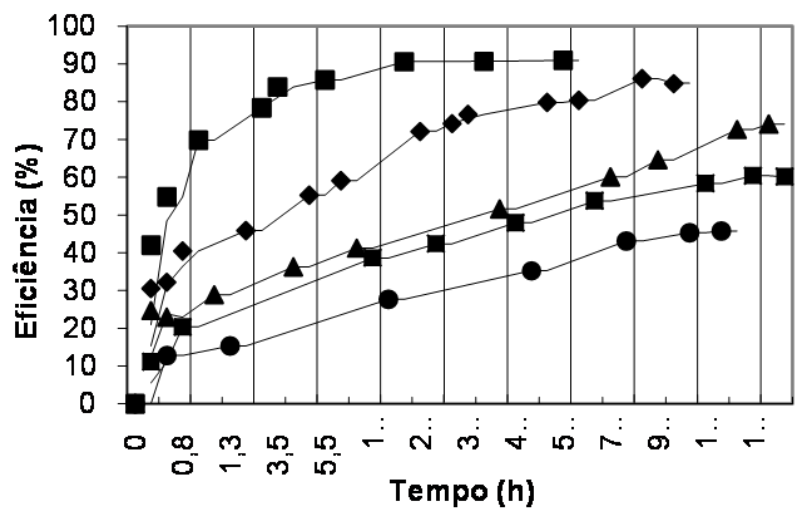

Figura 3 - Variação da eficiência em função do tempo nos diferentes ciclos de reuso do adsorvente. $\mathbf{\|}$ lociclo -2ociclo \3ociclo • 4ociclo •5ociclo

Analisando os gráficos de eficiência do adsorvente em função do tempo, observa-se que o adsorvente apresentou taxas de eficiência maiores sempre no primeiro tempo da amostragem e à medida que a absorbância da amostra diminuía esta taxa diminuía também até estabilização tornando inviável a continuação do teste, pois a taxa de variação era pouco significativa. Iniciando um novo ciclo, novamente a alta taxa de eficiência se elevava no primeiro tempo. Isso mostra que a taxa de eficiência de adsorção está diretamente ligada a concentração do adsorbato na solução também. A cada ciclo posterior houve queda nas taxas de eficiência e na eficiência máxima de cada teste, o que mostra um limite no número de ciclos de reuso, embora os quatro ciclos de reuso não tenham sido suficientes para saturar o adsorvente, pois como ilustra a figura 4 , no quinto ciclo do adsorvente ainda foi possível obter cerca de $46 \%$ de eficiência na remoção dos corantes da solução. 


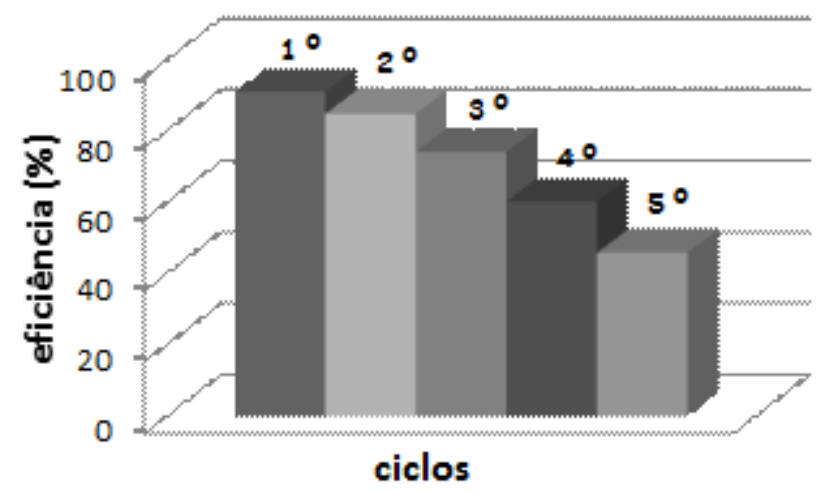

Figura 4 - Eficiência do adsorvente por ciclo de reutilização.

\section{Análises físico-químicas}

Foram realizadas análises físico-químicas de cor e DQO nas amostras do banho residual de tingimento sem o tratamento e pós-tratamento com as cinzas de casca de arroz nos cinco ciclos de reuso do adsorvente. A tabela 1 mostra os resultados obtidos, comparando-se cada ciclo com os dados do banho residual bruto do tingimento.

Quanto a DQO a maior redução foi obtida no ciclo $\mathrm{n}^{\mathrm{o}} 03$ de reuso da cinza, correspondendo a $76,5 \%$ e a menor foi no ciclo $\mathrm{n}^{\circ} 04$ com uma redução de 67,3\%. Ambos os parâmetros Cor e DQO não possuem parâmetro legal na emissão de efluentes líquidos em corpos receptores, porém servem como indicadores da qualidade do tratamento para monitoramento interno.

Comparando com a literatura constatou-se que estes valores obtidos de DQO foram próximos. Ahmad e Hameed [5] apresentaram resultados de remoção máxima de DQO de 75,2\% em seus experimentos de tratamento de efluentes têxteis reais através de processo de adsorção com carvão ativado de restos de bambu.

Mahmoud, E. K. [25] tratando diversos tipos de efluentes através do processo convencional de coagulação utilizando $\mathrm{FeCl}_{3}$ e $\left(\mathrm{Al}_{2}\left(\mathrm{SO}_{4}\right)_{3} \mathrm{n} \mathrm{H}_{2} \mathrm{O}\right)$ obteve em seus experimentos redução máxima de $70,1 \%$ da DQO. Analisando os resultados dos dois autores com o obtido neste experimento verificou-se que todos os resultados são semelhantes.

Oliveira e Leão [27] avaliando o método Fenton na biodegradabilidade de efluente do beneficiamento textil (purga e tingimento) de malhas de PES, obtiveram reduções menores de DQO, variando de 55 a $11 \%$ dependendo das condições de tratamento e da natureza do efluente quanto a origem purga ou tingimento.

Além da análise quantitativa da cor, é importante também a avaliação visual, pois é a primeira impressão que causa nos corpos receptores, sendo o primeiro parâmetro para liberação. A figura 5 permite a avaliação visual do tratamento, mostrando desde o efluente bruto até o ciclo $\mathrm{n}^{\circ} 05$. Observa-se uma maior redução de cor no ciclo $\mathrm{n}^{\circ} 01$ de tratamento, sendo de aproximadamente $91 \%$. Os resultados das análises de cor do ciclo $\mathrm{n}^{\circ} 02$ e $\mathrm{n}^{\circ} 03$ ficaram muito próximos, porém analisando visualmente estas amostras verifica-se que a amostra do ciclo $n^{\circ} 03$ está visualmente mais colorida. A presença de uma concentração mais acentuada de corante é perceptível nos ciclos $n^{\circ} 04$ e $n^{\circ} 05$ de reuso do adsorvente, mas no quinto ciclo de reuso da cinza ainda obteve-se uma redução de cor de aproximadamente $57 \%$.

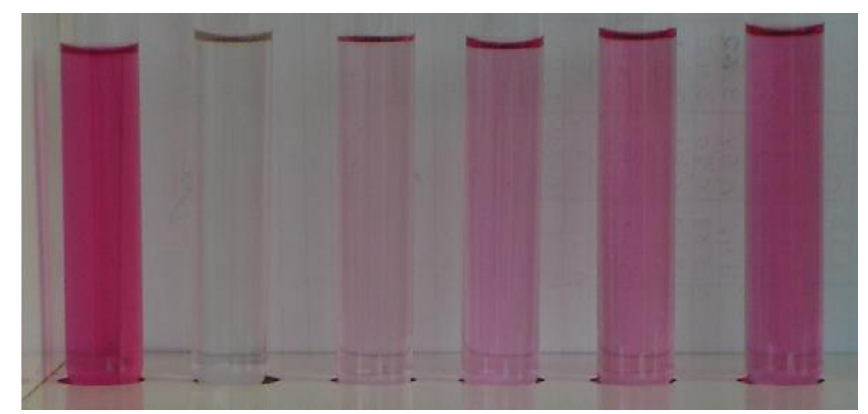

Figura 5 -Fotografia das amostras dos banhos de tingimento para análise visual dos diferentes ciclos de tratamento 
Tabela 1. Resultados das análises físico-químicas das amostras dos banhos de tingimento.

\begin{tabular}{|c|c|c|c|c|}
\hline Amostra & $\begin{array}{l}\text { Média da } \\
\text { Cor }(\text { PtCo })\end{array}$ & $\begin{array}{l}\text { Desvio } \\
\text { Padrão }\end{array}$ & $\begin{array}{c}\text { Média da } \\
\text { DQO (mg } \\
\left.\text { de } \mathrm{O}_{2} / \mathrm{L}\right)\end{array}$ & $\begin{array}{l}\text { Desvio } \\
\text { Padrão }\end{array}$ \\
\hline $\begin{array}{c}\text { Banho bruto de } \\
\text { tingimento (residual) }\end{array}$ & 1585 & 2,2 & 327 & 2,8 \\
\hline $\begin{array}{l}\text { Após tratamento no } 1^{\circ} \\
\text { ciclo do adsorvente }\end{array}$ & 262 & 1,4 & 93 & 1,6 \\
\hline $\begin{array}{l}\text { Após tratamento no } 2^{\circ} \\
\text { ciclo do adsorvente }\end{array}$ & 340 & 0,8 & 96 & 2,2 \\
\hline $\begin{array}{l}\text { Após tratamento no } 3^{\circ} \\
\text { ciclo do adsorvente }\end{array}$ & 337 & 2,9 & 77 & 2,9 \\
\hline $\begin{array}{l}\text { Após tratamento no } 4^{\circ} \\
\text { ciclo do adsorvente }\end{array}$ & 495 & 2,8 & 107 & 1,4 \\
\hline $\begin{array}{l}\text { Após tratamento no } 5^{\circ} \\
\text { ciclo do adsorvente }\end{array}$ & 667 & 1,6 & 95 & 1,4 \\
\hline
\end{tabular}

* Valores de referência ao banho residual de tingimento 


\section{CONCLUSÕES}

Baseado nos resultados obtidos pode-se afirmar que as cinzas de casca de arroz como adsorvente apresentou uma alta eficiência para o primeiro ciclo de tratamento, ficando isso claro na análise visual da amostra tratada e nos dados quantitativos (91\% de remoção da cor). Os testes com os ciclos posteriores apresentaram uma coloração perceptível aos olhos, porém é válido ressaltar que mesmo no quinto ciclo de reuso do adsorvente ainda obteve-se uma eficiência de quase $50 \%$. Constatou-se também que a redução de DQO do banho de tingimento têxtil tratado com as cinzas de casca de arroz foi elevada com valores aproximados a de outros processos, como é o caso do processo de coagulação que é muito utilizado em ETE's da indústria têxtil.

Por fim considera-se que apenas a amostra de banho residual de tingimento tratada no ciclo $\mathrm{n}^{\circ}$ 01 com este adsorvente estaria perfeitamente apta a ser lançada em algum corpo receptor sem que houvesse impacto visual. Levando-se em consideração que esta amostra tratada ficou incolor, a qualidade desta água tratada permitiria um estudo visando a reutilização deste banho residual de tingimento em um novo tingimento.

\section{AGRADECIMENTOS}

Lunelli Beneficiamentos Têxteis: resíduos líquidos (banho de tingimento) e análises físicoquímicas (DQO e Cor Aparente PtCo). Indústria catarinense de beneficiamento de arroz.

\section{REFERÊNCIAS}

[1] Kunz, A., Zamora-Peralta, P., Quím. Nova. 25 (2002) 78 .

[2] Souza, A. F., Rosado, F. R., Revista em agronegócios e meio ambiente. 2 (2009) 121.

[3]Tunussi,J.L.;Sobrinho,P.A.;http://www.agualati noamerica.com/docs/pdf/6Aidis\%20Textile.pdf, acessado em 01 de junho de 2009.

[4] Barcellos, I. O., Giovanella, R. F., Chiarello, L. M., Blosfeld, A. M. Dynamis. 15 (2009)1.

[5] Ahmad, A.A, Hameed, B.H., Journal of Hazardous Materials. 172 (2009)1538.
[6] Khaled, A., Nerm, A. E., EL-sikaily, A., Abdelwahab, O., Journal of Hazardous Materials.165 (2009)100.

[7] Dulman, V., Cucu-man, S. M., Journal of Hazardous Materials. 162 (2009)1457.

[8] Rutz, E. G., Carvalho C. F, Pires, C.S; Curiel, G.L, Revista Escola de Minas. 61(4) (2008) 443.

[9] Barcellos, I.O., L. M. Chiarello, G. Spengler, D. E. Roza. Acta Sci. Technology. 31(11) (2012) No prelo.

[10] Biavath, A. C, Blosfeld, A. M., Barcellos, I. O., $16^{\circ}$ Encontro de Química da Região Sul(SBQ-SUL). Blumenau, Brasil. Resumo de congresso (2008).

[11]ARROZBRASILEIRO.

http://www.arroz.agr.br/site/estatisticas/html/ tab103. htm, acessado em 12 de julho de 2010.

[12] Foletto, E. L., Quím. Nova. 28 (2005) 1055.

[13] Menezes, R, R, Neto E, F, Fernandes M.C, Souto, P.M, Kiminani, R. H. G. A. Cerâmica.54 (330) (2008) 373.

[14] Zucco, L. L., Beraldo, A. L.. Engenharia Agrícola. 28(2) (2008) 217.

[15] Srivastava, V. C., Mall, I. D., Mishra, I. M.. J. Chem. Eng. 54 (2009) 705.

[16] Lakshmi, U. R., Srivastava, V. C., Mall, I. D., Lataye, D. H. Journal of Environmental Management. 90 (2009) 710.

[17] Lima, É. C., Cardoso, N, Dissertação de Mestrado, UFRGS, Brasil (2010).

[18] Oliveira, B.P, Soares, A.B, Nagipe P. http://www. abq.org.br/cbq/2008/trabalhos/13/13413-4431.htm, acessado em 11 de junho de 2009.

[19] Chaves, T. F, et al Congresso de iniciação científica, São Carlos. Anais de eventos, UFSCar. 4 (2008) 998.

[20] Sharma, P., Kaur, R.; Baskar, C., Chung, W.. Desalination. 259 (2010) 249.

[21] Ferro, Valdir P., Silva, Leonardo, Wiebeck, H.. Polímeros: Ciência e Tecnologia. 17(3) (2007) 240.

[22] Barcellos, I. O., Andreaus, J., Battisti, A.M., Borges, J.K., Polímeros: Ciência e Tecnologia.18 (3) (2008) 215.

[23] Wong, P. W., Teng, T. T., Norulaini, N. A. R. N.; Water Qual. Res. J.42 (2007) 54. 
[24] Souza, C. L., Peralta-zamora, P., Engenharia Sanitária Ambiental. 11(1) (2006).

[25] Bertazzoli, R., Pelegrini, R.. Quím. Nova. 25 (2002) 477.

[26] Mahmoud, E. K., Polish J. of Environ. Stud. 18 (2009), 651.

[27] Furlan, F. R.. Dissertação Mestrado em Engenharia Química. Universidade Federal de Santa Catarina, Florianópolis. Brasil (2008).

[28] Ignachewski, F., Fujwara, S., T. Fujwara, Luiz, F. Cótica, Lívia M. C, Tauchert, Peraltazamora, P., Quim. Nova, 33(2010) 1640.

[29] Oliveira, D.M., Leão, M.M.D., Quím. Têxtil. 100 (2010) 60.

[30] Gutierrez MC, Crespi M, Lopes-grimau J, Valldeeperas J.,Quim. Têxtil. 87 (2007)39.

[31] Silva, M. R. A. ;da, Oliveira, M. C. de ; Nogueira, R. F. P. Eclet. Quím., 29, (2004),19.

[32] Barcellos, I. O., Giovanella, R. F., Chiarello, L. M., Blosfeld, A. M. Quím. Têxtil. 91(2008) 54. [33] Barcellos, I. O.; Chiarello, L. M.. Dynamis, 15, (2009),37. 